\title{
Big feet in Polynesia: a somatometric study of the Tongans
}

\author{
ERI GONDA $^{1 *}$, KAZUMICHI KATAYAMA $^{2}$ \\ ${ }^{1}$ Division of Morphology and Evolution, Primate Research Institute, Kyoto University, \\ Inuyama-city, Aichi Prefecture, 484-8506 Japan \\ ${ }^{2}$ Department of Zoology, Graduate School of Science, Kyoto University
}

Received 22 September 2003; accepted 13 October 2005

\begin{abstract}
Somatometric research was conducted in Tonga, Polynesia, with a focus on foot and hand size and proportions. Data were taken on 140 adults ( 90 females and 50 males) and compared with those of other population groups. In addition to their heavy body-build, Tongans were found to have significantly longer and wider feet and hands than the Japanese, French, Australian Aborigines, or Bamanann-Fulbe West Africans. The significance of these physical characteristics of Polynesians is discussed from a micro-evolutionary viewpoint.
\end{abstract}

Key words: Tonga, Polynesians, foot measurements, hand measurements

\section{Introduction}

Polynesians are known to have distinctive and relatively homogeneous physiques despite inhabiting a large area of the Pacific Ocean (Shapiro, 1943; Howells, 1973; Houghton, 1996; Katayama, 1996). Howells (1970) strongly suggested physical homogeneity on the basis of somatometric multivariate analyses of a total of 151 human population groups in Oceania, including those from New Guinea and Australia. Tagaya and Katayama (1988) also concluded, on the basis of multivariate craniometric analyses, that Polynesians can be easily distinguished from other Oceanic (e.g. Micronesians and Melanesians) and Asian populations.

Polynesians are also known for their unique combination of physical characteristics: tall stature, a large muscular body, a robust skeleton, and a strong tendency toward obesity (Katayama, 1996). Katayama (1996) proposed that these characteristics were the result of hypermorphosis. He pointed out the skeletal resemblance between prehistoric Polynesians and a large-sized modern Japanese Sumo wrestler examined by Suzuki et al. (1986), especially the relatively large size of the skeletal elements of the hands and feet.

Although a number of anthropometric studies have been conducted on Polynesians (e.g. Buck, 1922-23; Sullivan, 1922; Shapiro and Buck, 1936; Howells, 1970; and Katayama, 1982), none has dealt with the hands and feet.

The objective of this study is to describe the metric features of the hands and feet of the Polynesian people living in the Kingdom of Tonga. This study is a part of a larger series of somatometric studies that have been conducted during the course of the Kyoto University Tonga Research Project of 2000 to 2003; a total of 366 persons were measured in 2001. Adult male and female Tongans aged 18 years or older were

* Corresponding author. e-mail: gonda@pri.kyoto-u.ac.jp phone: +81-568-61-5775; fax: +81-568-61-5775

Published online 28 January 2006

in J-STAGE (www.jstage.jst.go.jp) DOI: 10.1537/ase.00097 the subjects of analysis, and the metric attributes of their hands and feet were compared with published accounts of other populations.

\section{Material and Methods}

The Kingdom of Tonga is situated in the westernmost part of the Polynesian triangle. It consists of more than 170 islands segregated into three major island groups: Tongatapu to the south, Ha'apai to the north, and Vava'u further north (Figure 1). According to the national population census of 1996 (Statistics Department, Kingdom of Tonga, 1999), the total population is 97,784: 71,913 in Tongatapu, 8,138 in Ha'apai, and 17,733 in Vava'u. In that census, more than $96 \%$ of the population was reported to be of Polynesian descent.

\section{Subjects}

The somatometric data analyzed in this study come from 140 adult individuals ( 90 females and 50 males) ranging in age from 18-68 years, from Nuku'alofa, the capital city of Tonga, and Lifuka island, Ha'apai. Information regarding date of birth, birthplace, parents' ethnicity, and occupation were recorded for each subject at the time of measurement. The average age was 32.1 and 31.3 years for the male and female subjects, respectively. The subjects were selected at random and did not include any persons of European or Asian ancestry. Their occupations varied-farmers, medical workers, public officers, housewives, students, and so on. For the purpose of the final analysis, all subjects were combined for each sex, because of absence of statistically significant differences (by $t$-test) in each measurement between locations or between age classes. However, outliers with values of more than 3 standard deviations (SD) from the means were excluded from the analysis.

\section{Measurements and indices}

Stature, body mass, foot length, foot breadth, hand length, and hand breadth were measured. For the foot and hand met- 


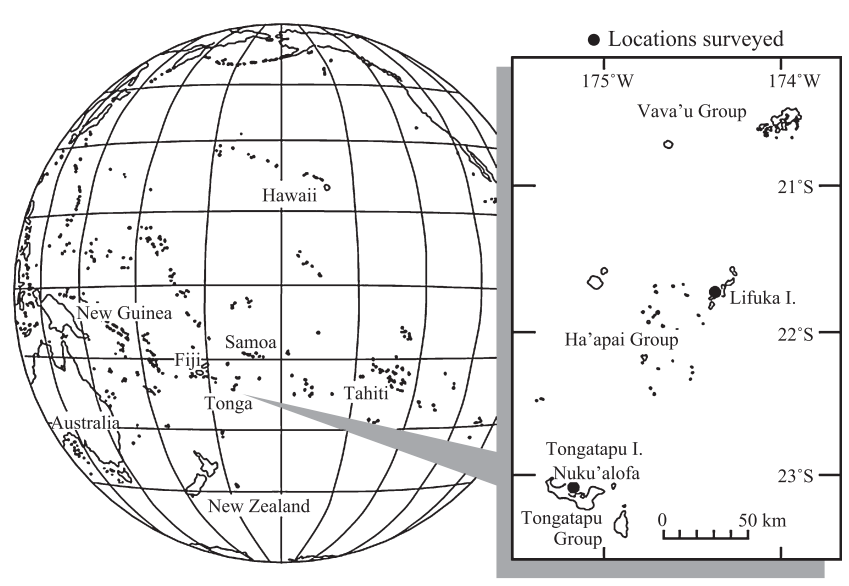

Figure 1. Map of Oceania and the two locations of the anthropometric survey in Tonga.

rics, the right side was measured. Stature was measured using a standard anthropometer (GPM Co. Ltd.). Body mass was measured with a scale with subjects in light clothing and bare feet. A sliding caliper (GPM Co. Ltd.) was used to measure hand length and breadth, while the subjects sat and placed their hands on a desk.

Hand dimensions were measured to the nearest $\mathrm{mm}$, according to the definition of the National Institute of Bioscience and Human Technology (NIBH, 1994). Hand length is defined as the distance between the second-most distal crease on the palm side of the wrist and the reference point dactylion. Hand breadth is defined as the distance between reference points metacarpale ulnare and metacarpale radiale, taken with all fingers of rays 2 to 4 extended forwards in the same direction.

Foot measurements were taken, in $\mathrm{mm}$, from contour drawings of the foot. Each subject was instructed to stand barefoot with his or her feet 10-15 cm apart. Foot length was defined as the projected distance from the reference points acropodion to pternion (JLIA, 1988), taken parallel to the foot axis (the line connecting the tip of the second toe and pternion). Foot breadth was defined as the projected distance between reference points metatarsale tibiale and metatarsale fibulare.

A total of seven indices were calculated as follows:

Foot index $=[($ foot breadth $) /($ foot length $)] \times 100$,

Hand index $=[($ hand breadth $) /($ hand length $)] \times 100$,

Relative foot length (RFL) $=[($ foot length $) /($ stature $)] \times 100$

Relative foot breadth (RFB) $=[($ foot breadth $) /($ stature $)] \times 100$,

Relative hand length (RHL) $=[($ hand length $) /($ stature $)] \times 100$,

Relative hand breadth (RHB) $=[($ hand breadth $) /($ stature $)] \times 100$,

Body mass index (BMI) $=($ body mass in $\mathrm{kg}) /(\text { stature in } \mathrm{m})^{2}$.

\section{Data comparison}

The comparative data used in the present study were as follows. The Japanese data (both foot and hand, and abbreviated JP) were combined into one data set from a series of studies on Japanese populations (Kouchi, 1998). The French foot data (abbreviated FR) were taken from staff and students at the Cognitive Neuroscience Laboratory, Marseille (Kouchi, 1998). The Australian Aborigine foot data (abbreviated AA) were obtained from residents living in Arnhem Land, Northern Territory (Kouchi, 1998). The BamanannFulbe data (both foot and hand, and abbreviated BF) were obtained from residents living in villages situated south of the capital of Bamako, Mali Republic (Adachi et al., 1993).

The significance of differences between means was examined by $t$-tests. The RFL, RFB, RHL, RHB, and hand index of all the comparative groups and the foot index of the BF sample were calculated using the sample means. Because of this, statistical tests were not conducted with these indices.

\section{Results}

Table 1 shows the basic statistics of the somatometric variables. Males were significantly larger than females

Table 1. Comparison of stature, body mass, and foot and hand measurements of the Tongan people and other ethnic groups

\begin{tabular}{|c|c|c|c|c|c|c|}
\hline & Stature $(\mathrm{cm})$ & Body weight $(\mathrm{kg})$ & Foot length (mm) & $\begin{array}{l}\text { Foot breadth } \\
\qquad(\mathrm{mm})\end{array}$ & Hand length (mm) & $\begin{array}{l}\text { Hand breadth } \\
(\mathrm{mm})\end{array}$ \\
\hline \multicolumn{7}{|l|}{ Male } \\
\hline TONGAN $(n=50)$ & $174.8(5.73)$ & $93.2(17.08)$ & $279.2(12.52)$ & $117.9(6.14)$ & $203.2(8.33)$ & $91.6(4.12)$ \\
\hline Japanese $^{1}(n=478)$ & $168.7(5.97)^{* *}$ & $63.9(8.59)^{* *}$ & $247.9(10.40)^{* *}$ & $101.9(4.62)^{* *}$ & $180.8(7.23)^{* *}$ & $81.9(3.12)^{* *}$ \\
\hline $\operatorname{French}^{2}(n=31)$ & $177.1(6.88)$ & $72.6(11.85)^{* *}$ & $264.2(10.44)^{* *}$ & $105.8(5.92)^{* *}$ & & \\
\hline Bamanann-Fulbe $^{3}(n=86)$ & $173.1(6.82)$ & $62.5(6.6)^{* *}$ & $271.0(13.1)$ & $104.5(5.90)^{* *}$ & $199.5(10.4)^{*}$ & $86.5(3.8)^{* *}$ \\
\hline Australian Aborigines ${ }^{4}(n=33)$ & & & $259.1(12.47)^{* *}$ & $102.8(4.32)^{* *}$ & & \\
\hline \multicolumn{7}{|l|}{ Female } \\
\hline TONGAN $(n=90)$ & $165.3(5.61)^{* * a}$ & $88.8(16.80)$ & $259.6(10.50)^{* * a}$ & $106.8(5.80)^{* * a}$ & $189.1(8.04)^{* * a}$ & $81.8(3.79)^{* * 2}$ \\
\hline Japanese $^{1}(n=410)$ & $155.9(4.86)^{* *}$ & $51.5(5.99)^{* *}$ & $227.4(9.02) * *$ & $93.1(4.38)^{* *}$ & $167.8(7.93)^{* *}$ & $73.6(3.24)^{* *}$ \\
\hline French $^{2}(n=31)$ & $162.2(6.04)$ & $58.8(4.95)^{* *}$ & $237.4(10.60)^{* *}$ & $91.6(4.61)^{* *}$ & & \\
\hline Bamanann-Fulbe ${ }^{3}(n=92)$ & $161.3(5.18)$ & $54.4(6.3)^{* *}$ & $249.6(10.6)^{* *}$ & $96.1(5.2)^{* *}$ & $185.7(9.0)$ & $80.3 \quad(3.8)$ \\
\hline Australian Aborigines ${ }^{4}(n=32)$ & & & $238.6(9.77)^{* *}$ & $91.1(4.32)^{* *}$ & & \\
\hline
\end{tabular}

Values are the means; standard deviations in parentheses.

$*, P<5 \%$ level; $* *, P<1 \%$ level; indicates difference from the Tongan mean

$* *$ a,$P<1 \%$ level; indicates sex difference.

${ }^{1}$ NIBH (1994) and Kouchi (1998), ${ }^{2,4}$ Kouchi (1998), ${ }^{3}$ Adachi et al. (1993). 
Table 2. Comparison of the BMI and foot and hand indices of the Tongan people and other ethnic groups

\begin{tabular}{|c|c|c|c|c|c|c|c|}
\hline & BMI & Foot index & RFL & RFB & Hand index & RHL & RHB \\
\hline \multicolumn{8}{|l|}{ Male } \\
\hline TONGAN $(n=50)$ & $30.4(4.95)$ & $42.3(2.10)$ & $16.0(0.39)$ & $6.7(0.32)$ & $45.0(1.86)$ & $11.6(0.32)$ & $5.2(0.24)$ \\
\hline Japanese $^{1}(n=109)$ & 22.5 & $41.1(1.66)^{* *}$ & 14.7 & 6.0 & 43.0 & 11.1 & 4.8 \\
\hline French $^{2}(n=31)$ & 23.1 & $40.0(1.69)^{*}$ & 14.9 & 6.0 & & & \\
\hline $\begin{array}{l}\text { Bamanann-Fulbe }{ }^{3}(n=86) \\
\text { Australian Aborigines }^{4}(n=33)\end{array}$ & 20.9 & $\begin{array}{l}38.6 \\
39.7(1.84)^{* *}\end{array}$ & 15.7 & 6.0 & 43.4 & 11.5 & 5.0 \\
\hline \multicolumn{8}{|l|}{ Female } \\
\hline TONGAN $(n=90)$ & $32.5(5.78)$ & $41.2(1.88)$ & $15.7(0.48)$ & $6.5(0.35)$ & $43.3(1.70)^{* a}$ & $11.4(0.39)$ & $5.0(0.20)$ \\
\hline Japanese $^{1}(n=107)$ & 21.2 & $41.0(1.80)$ & 14.6 & 6.0 & 42.0 & 10.9 & 4.6 \\
\hline French $^{2}(n=31)$ & 22.3 & $38.6(1.48)^{* *}$ & 14.6 & 5.6 & & & \\
\hline $\begin{array}{l}\text { Bamanann-Fulbe }{ }^{3}(n=92) \\
\text { Autralian }\end{array}$ & 20.9 & 38.5 & 15.5 & 6.0 & 43.2 & 11.5 & 5.0 \\
\hline
\end{tabular}

Values are the means; standard deviations in parentheses. Italicized numbers were calculated from the published means.

$*, P<5 \%$ level; **, $P<1 \%$ level; indicates difference from the Tongan mean.

$*$ a,$P<5 \%$ level; indicates sex difference.

${ }^{1}$ NIBH (1994) and Kouchi (1998), ${ }^{2,4}$ Kouchi (1998), ${ }^{3}$ Adachi et al. (1993).

$(P<0.01)$ in all measurements except body mass. For the indices, a significant difference between the sexes was found only in the hand index $(P<0.05)$, i.e. males had greater values than females. Mean BMI values of 30.4 for males and 32.5 for females were in the range of the 'overweight' category according to the World Health Organization standard (WHO, 1990).

The Tongans were compared with four other populations (Table 1, Table 2). The Tongans were significantly heavier than all the other groups in both sexes $(P<0.01)$. Tongan females were the tallest among all groups, while the Tongan males were the second tallest. However, with stature, a statistically significant difference was found only between the Tongans and JP in both sexes $(P<0.01)$.

Both male and female Tongans had significantly longer and wider feet than all other groups $(P<0.01)$, except for male foot length compared with BF. The Tongans had a larger foot index than in JP $(P<0.01$ in males but not significant in females $)$, FR $(P<0.05$ in males and $P<0.01$ in females $)$, or AA $(P<0.01$ in both sexes). Although $t$-tests for RFL and RFB could not be performed, Tongans had relatively larger and wider feet than the other population groups. The greater relative width of the Tongan foot is revealed in Figure 2. The mean values of the other groups are located well below and to the left of the scatter of the Tongan subjects, indicating not only a smaller but also a relatively narrower foot than that of the Tongans.

Similar to the condition seen with the foot, the hands of the Tongans were significantly longer and wider than in the two comparative groups that could be statistically compared (but with the exception of the BF females). With regards to RHL and RHB, the mean values of the Tongans were comparable to those of BF, and greater than those of JP in both males and females. Average hand index was greater in the Tongans than in JP or BF, especially in males.

\section{Discussion}

The results of the present study show that, in comparison with the other population groups, the Tongans are characterized not only by their heavy body-build, but also by their
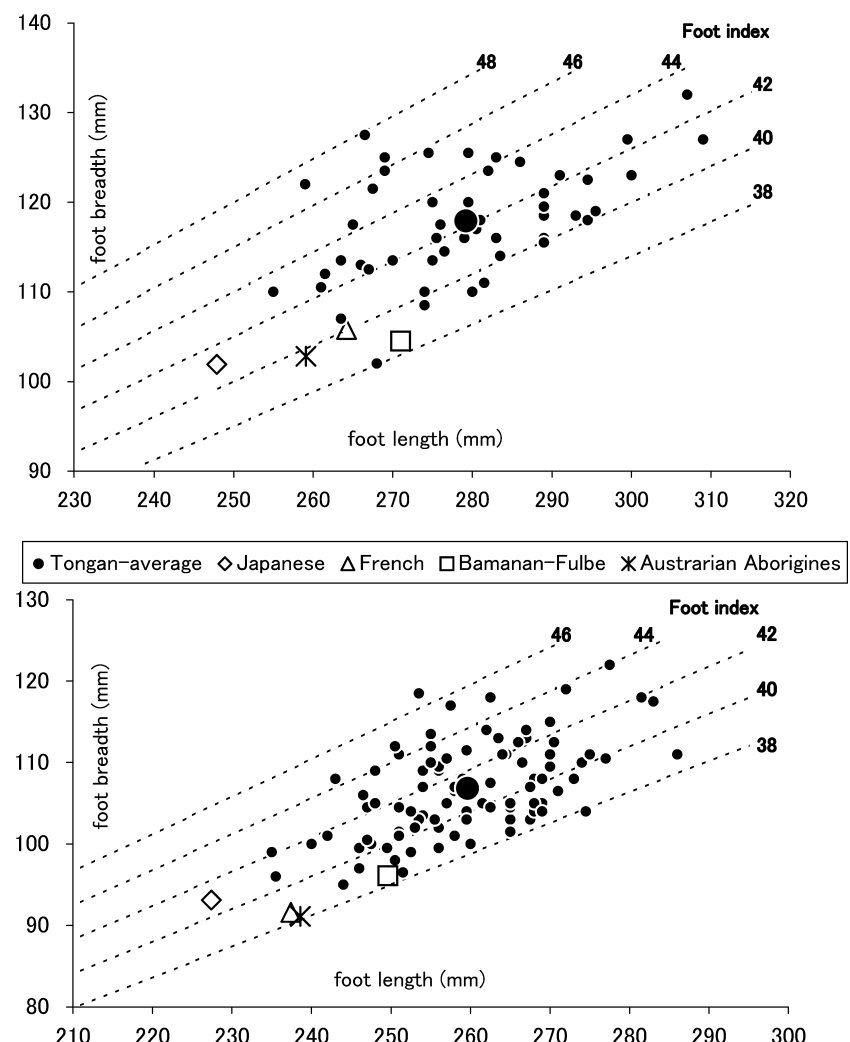

Figure 2. Scatter diagram of foot length and foot breadth for males (upper) and females (lower). Dotted lines indicate foot index values.

longer and wider feet. This was the case for both absolute size and for size relative to stature (Table 1, Table 2, Figure 2). Although the present comparisons are limited, the hands of the Tongans also tended to be longer and wider than those of the other populations (Table 1, Table 2).

The morphological characteristics of humans vary widely across location and time, a fact that has been discussed at least since Aristotle. Somatometric variation, generally, can 
be considered to be underlain by a variety of factors, some of which relate to the micro-evolutionary history of local populations. The history of human migration to the Pacific islands has been discussed for several decades. As for the origin of the Tongan people (Polynesian), one hypothesis that has become widely accepted, based on archaeological evidence, is that the islands of Tonga had been settled by Neolithic human populations of the so-called 'Lapita' people by 1200-1100 BC (Kirch, 1997). The 'Lapita' people are considered to be Austronesian speakers, who originated from Southeast Asia and immigrated to the islands of 'Remote Oceania' (Green, 1991), including Fiji, Samoa, and Tonga, at about 1600 to 500 BC (Diamond, 1998). Current archaeological, linguistic, and genetic studies (e.g. Bellwood, 1991; Kelly, 1996; Kirch, 1997) support this hypothesis.

Recent studies based on a variety of approaches suggest that modern Polynesians derive from small-sized ancestral populations that were characterized by a large and heavy body-build, such characteristics probably having been acquired through selection associated with natural disasters. The results of genetic and anthropometric analyses (e.g. Howells, 1970; Tagaya and Katayama, 1988; Cavalli-Sforza et al., 1994) suggest that Polynesians have origins different from that of the other Oceanic populations, such as Melanesians and Micronesians. Cavalli-Sforza et al. (1994) proposed the following hypothesis concerning the history of the Polynesian populations: (1) the founders came from relatively small populations, (2) there were frequent bottlenecks, caused by natural disasters such as typhoons, and (3) there were later additions to the populations from subsequent migrants. This set of hypotheses is consistent with the so-called homogeneous body-build of the Polynesians (Shapiro, 1943: Houghton, 1996).

Houghton (1990) hypothesized that the heavy body-build of the Polynesians was the result of adaptation to cold conditions. Although most of the Polynesian islands are within the tropical region of the Pacific Ocean, the climate is windy and the sensory temperature is low. Houghton (1990) showed that the somatometric characteristics of the Polynesians were similar to those of the higher-latitude Asian populations. Cavalli-Sforza et al. (1994), referring to the report by Morton et al. (1972), stressed that bottlenecks in the population history of Polynesians would have occurred as a result of famine after a typhoon. If that was the case, heavy body-build could also be considered to have evolved as an adaptation to famine, that is, as a reservoir of nutrients. Polynesian populations would, then, not only be characterized by random genetic drift, but also by an adaptive physique, i.e. heavy body-build.

The Polynesians' big feet and hands may be related to their body-build. However, larger body mass per se cannot explain the larger feet of the Polynesians. Katayama (1996) suggested that the heavy body-build of the Polynesians was the result of a special growth pattern 'hypermorphism', as conceived in heterochrony (e.g. McNamara, 1997). Katayama (1996) based his reasoning on the similarities of skeletal size and proportions, especially those of the extremities, between the Polynesians and a large Japanese individual with gigantism (a deceased Sumo wrestler, 'Dew- agatake', Suzuki et al., 1986). Enlargement of the extremities is known to be one of the common clinical features of gigantism and acromegaly (e.g. Fitzgerald, 1992). Katayama (1996) suggested that the excessively developed body of the Polynesians is produced by their elongated juvenile and adolescent growths. Although gigantism is caused by an endocrinological disorder, genetic modifications mimicking it could have produced adaptive physical characteristics, which would have been selected for during the micro-evolutionary history of the Polynesians. It is possible that the Polynesians' big feet, perhaps obtained by such growth mechanisms, would be adaptive in supporting their heavier bodies. The great RFL and RFB values (Table 2), the most distinctive features of their feet, indicate that the Tongans have long and wide feet even relative to their tall and heavy bodies.

In conclusion, the ancestors of the Polynesians were certain to have experienced severe and inescapable natural disasters and famine, which probably caused bottlenecks during their population history. Selection that occurred during such bottlenecks - caused, for example, by the windy climate - would be likely to favor the heavy body-build of the Polynesians. The genetic modification underlying such an adaptation could have resulted in a 'hypermorphic' growth pattern, which produced not only a heavy body-build but also the characteristically large feet of the Polynesians. This hypothesis must be examined by further studies, especially those that investigate the growth pattern of the Polynesians.

\section{Acknowledgments}

We are very grateful to the numerous people of the Kingdom of Tonga who kindly became subjects and cooperated with our anthropometric research. We also thank Dr Y. Hamada and the staff of the Section of Morphology at the Primate Research Institute, Kyoto University for constructive advice. The present work was financially supported by Grant-in-Aid for Scientific Research (A) (No. 12371010) from the Japan Society for the Promotion of Science (JSPS).

\section{References}

Adachi K., Kusumoto A., Kawada J., and Hosaka M. (1993) Anthropometric study of some West-African ethnic groups in relation to techniques of the body. African Studies, 43: 1-30 (in Japanese).

Bellwood P. (1991) The Austronesian dispersal and the origin of languages. Scientific American, 265: 88-93.

Buck P.H. (Te Rangi Hiroa) (1922-23) Maori somatology. Journal of the Polynesian Society, 31 and 32: 1-151.

Cavalli-Sforza L.L., Menozzi P., and Piazza A. (1994) The History and Geography of Human Genes. Princeton University Press, New Jersey.

Diamond J.M. (1998) Express train to Polynesia. Nature, 336: 307-309.

Fitzgerald P. (1992) Handbook of Clinical Endocrinology. Appleton \& Lange, Norwalk, Connecticut.

Green R. (1991) Near and Remote Oceania: disestablishing "Melanesia" in culture history. In: Pawley A. (ed.), Man and a Half: Essays in Pacific Anthropology and Ethnobotany in Honour of Ralph Bulmer. The Polynesian Society, Auckland. Houghton P. (1990) The adaptive significance of Polynesian body 
form. Annals of Human Biology, 17: 19-32.

Houghton P. (1996) People of the Great Ocean: Aspects of Human Biology of the Early Pacific. Cambridge University Press, Cambridge.

Howells W.W. (1970) Anthropometric grouping analysis of Pacific peoples. Archaeology and Physical Anthropology in Oceania, 5: $192-217$.

Howells W.W. (1973) The Pacific Islanders. Weidenfeld \& Nicolson, London.

JLIA (Japan Leather and Leather-Good Industries Association) (1988) Report of the research and development on foot studies. Tokyo (in Japanese).

Katayama K. (1982) Anthropological research. In: Hatanaka S. and Shibata N. (eds.), Reao Report: A Study of the Polynesian Migration to the Eastern Tuamotus. The University of Kanazawa, Kanazawa.

Katayama K. (1996) Polynesians the hypermorphic Asiatics: a scenario on prehistoric Mongoloid dispersal into Oceania. Anthropological Science, 104: 15-30.

Kelly K. (1996) The end of the trail: the genetic basis for deriving the Polynesian peoples from Austronesian speaking paleopopulations of Melanesian Near Oceania. In: Davidson J., Irwin G., Leach F., Pawley A., and Brown D. (eds.), Oceanic Culture History: Essays in Honour of Roger Green. New Zealand Journal of Archaeology, Dunedin North.

Kirch P.V. (1997) The Lapita Peoples: Ancestors of the Oceanic World. Blackwell, Cambridge, Massachusetts.

Kouchi M. (1998) Foot dimensions and foot shape: difference due to growth, generation and ethnic origins. Anthropological Science, 106 (Supplement): 161-188.

McNamara K.J. (1997) Shapes of Time: The Evolution of Growth and Development. The Johns Hopkins University Press, Bal- timore, Maryland.

Morton N.E., Lew R., Hussels I.E., and Little G.F. (1972) Pingelap and Mokil Atolls: historical genetics. American Journal of Human Genetics, 24: 277-289.

NIBH (National Institute of Bioscience and Human-Technology) (1994) Human body dimensions data for ergonomic design. Report of National Institute of Bioscience and HumanTechnology, 2: 1-236 (in Japanese).

Shapiro H.L. (1943) Physical differentiation in Polynesia. In: Coon C.S. and Andrews J.M. (eds.), Studies in the Anthropology of Oceania and Asia. Papers of the Peabody Museum of Archaeology and Ethnology, Volume 20, Cambridge, Massachusetts.

Shapiro H.L. and Buck P.H. (1936) The physical characters of the Cook islanders. Memoir of the Bernice P. Bishop Museum, Volume 12, No. 1, Honolulu.

Statistics Department, Kingdom of Tonga (1999) Population Census 1996: Report and General Tables. Nuku'alofa.

Sullivan L.R. (1922) A contribution to Tongan somatology; based on the field studies of E.W. Gifford and W.C. Mackern. Memoir of the Bernice P. Bishop Museum, Volume 8, No. 4, Honolulu.

Suzuki H., Baba H., and Kamiya T. (1986) Morphological study on the skeleton of a giant Sumo wrestler, the late Mr. Dewagatake. Journal of the Anthropology Society of Nippon, 94: 403-440 (in Japanese).

Tagaya A. and Katayama K. (1988) Craniometric variation in Polynesians: multivariate positioning of male crania from Mangaia, Cook Islands. Man and Culture in Oceania, 4: 7589.

WHO (World Health Organization) (1990) Diet, nutrition and the prevention of chronic diseases. WHO Technical Report Series, No. 797. WHO, Geneva. 